\title{
CRIANÇAS COM SÍNDROME DE DOWN: REFERENCIAÇÃO E MULTIMODALIDADE EM CONTEXTO LÚDICO
}

PAulo ViníCIUS ÁVILA-NÓBREGA*

Marianne Carvalho Bezerra CAVALCANTE**

\section{RESUMO}

Nosso intuito é apresentar o uso da referenciação multimodal (ÁVILANÓBREGA, 2017) de duas crianças com Síndrome de Down, no engajamento conjunto em contextos lúdicos. Acerca da SD, postulados de Pueschel (2002) serão apresentados. Sobre referenciação, mencionamos as relações da reiteração e da associação. Para tratar do que concebemos por multimodalidade, tomamos por base estudos de McNeill (1985) e, sobre engajamento conjunto, nos pautamos em estudos de Tomasello (2003). Nossa coleta de dados ocorreu na Clínica de Fonoaudiologia da Universidade Federal da Paraíba, e os vídeos contendo os dados coletados na clínica têm uma média de 30 minutos de duração.

PalaVRas-CHAVE: referenciação multimodal, Síndrome de Down, engajamento conjunto.

\section{INTRODUÇÃO}

Iniciamos este trabalho apontando para o fato de, no início do século $\mathrm{XX}$, alguns médicos pensarem que, se o período de máformação do bebê com Síndrome de Down (doravante, SD) ocorresse no início da gestação, a condição seria resultado de alguma influência do ambiente durante os primeiros meses de gravidez. Concepções equivocadas levaram a medicina a fazer conjecturas sobre as causas serem decorrentes do alcoolismo, da sífilis, da tuberculose (fatores

* Doutor em Linguística pelo Programa de Pós-graduação em Linguística (PROLING), da UFPB. João Pessoa/PB. e-mail: pvletras@gmail.com

** Doutora em Linguística pela Universidade Estadual de Campinas (UNICAMP), Campinas, São Paulo, Brasil. E-mail: marianne.cavalcante@gmail.com. 
muito comuns resultantes de outros problemas à época) ou decorrentes de algum tipo humano mais primitivo. Já no início dos anos 1930, com bases acertadas, alguns médicos suspeitavam ser a SD proveniente de problemas cromossômicos (PUESCHEL, 2002). Como naquela época as técnicas para o exame dos cromossomos não eram avançadas o suficiente para provar essa teoria, apenas em 1956 novos métodos laboratoriais tornaram-se disponíveis, permitindo aos cientistas a comprovação de que, em cada célula humana, havia 46 cromossomos, e não 48, como até aquele momento se acreditou.

Foi Jerome Lejeune, cientista francês, que, em homenagem a John Langdon Down, deu o nome "Síndrome de Down" aos indivíduos com características comuns da síndrome até aquele momento denominados "idiotas" (termo utilizado pela população grega para se referir aos indivíduos privados de convívio social, como, por exemplo, mulheres e deficientes). Lejeune relatou, três anos mais tarde, o fato de a criança com Down ter um pequeno cromossomo extra. Ele observou 47 cromossomos em cada célula das crianças analisadas, ao invés de 46, e, ao invés dos dois cromossomos 21 comuns, encontrou três cromossomos 21 em cada célula, resultando no termo trissomia 21. Cerca de 95\% das crianças com SD têm essa variação cromossômica. Em seguida, geneticistas detectaram haver outros problemas cromossômicos em crianças com a mesma síndrome, ou seja, a translocação e o mosaicismo.

A translocação ocorre em cerca de $3 \%$ a $5 \%$ das crianças com SD. Em crianças com essa variação, o número total de cromossomos nas células é 46, mas o cromossomo 21 extra está ligado a outro cromossomo, então, ocorre novamente um total de três cromossomos 21 presentes em cada célula. A diferença entre essa variação e a trissomia é que o terceiro cromossomo 21 não é livre, mas está ligado, ou translocado, a outro cromossomo, geralmente o 14 , o 21 ou o 22 . Todavia, o cromossomo 21 extra, ou parte dele, também poderia se aderir a outros cromossomos.

O terceiro tipo, e menos comum, de problemas cromossômicos em crianças com SD é o mosaicismo. Essa variação cromossômica geralmente ocorre em $1 \%$ das crianças e é considerada como resultado de um erro em uma das primeiras divisões celulares. Após o nascimento do bebê, encontram-se algumas células com 47 cromossomos e outras células com o número normal de 46. Vários 
estudiosos relatam o caso de algumas crianças com esse terceiro tipo de SD apresentarem traços menos acentuados da síndrome e o seu desempenho intelectual ser melhor do que a média para crianças com a trissomia 21 (PUESCHEL, 2002).

Já no que tange aos estudos do texto, mais especificamente sobre questões de referência e referenciação, passaram por vicissitudes atinentes ao interesse de filósofos da linguagem e linguistas, quando se preocuparam com o entendimento de estratégias textuais e de construção de sentidos, tanto na modalidade escrita da linguagem quanto nas interações face a face.

Acerca do termo multimodalidade, frisamos que vem sendo amplamente fomentado em pesquisas da Semiótica Social. A premissa desses estudos envolve a noção de que um texto falado nunca é somente verbal, mas também visual, pois combina expressões faciais, gestos, postura corporal e outros modos de interação (KRESS; VAN LEEUWEN, [1996], 2006).

Outra vertente promissora para os estudos da relação da produção de fala com os gestos é tida em Mcneill (1985; 1992; 2006). Para o autor, os gestos compartilham com a fala a mesma estrutura psicológica, uma combinação de produção em uma mesma matriz de significação (MCNEILL, 1985). Outro autor que caminha nessa mesma direção é Ruthtrof (2000), ao dizer que os gestos não são fenômenos acessórios do linguístico. Não se deve conceber a ideia de primazia da produção linguística (verbal), em detrimento da produção gestual, por serem entidades culturais.

Já em Ávila-Nóbrega (2017), a noção de referenciação multimodal vem sendo discutida como a negociação de sentidos de interagentes por meio do uso concomitante de modos de linguagem, não apenas o aspecto da produção vocal. Ou seja, com o uso do direcionamento do olhar, de variados gestos e produção vocal, é possível a negociação de sentidos em uma cena de engajamento entre os interagentes.

Tomando essas afirmações como base, o objetivo deste artigo é apresentar como ocorre o uso da referenciação multimodal por duas crianças com SD, em engajamento com terapeutas. Para tanto, discorreremos de forma breve a respeito de conceitos-chave como, por exemplo, referenciação, multimodalidade e engajamento conjunto. 
É importante destacar que os contextos situacionais analisados para este trabalho são de momentos lúdicos na clínica fonoaudiológica. As duas crianças ${ }^{1}$ frequentam os atendimentos semanalmente, como parte do projeto Letramento em Pauta: Intervenção Fonoaudiológica em sujeitos com SD. ${ }^{2}$ Os encontros dessas crianças foram iniciados no ano de 2014 e continuam ocorrendo, pelo menos até o momento da produção deste artigo. Para a nossa coleta, foram filmados seis atendimentos de $\mathrm{CA}$ e de $\mathrm{CC}$ e cinco encontros de $\mathrm{CB}$, pois, à época, o projeto entrou em férias.

Os dados coletados foram armazenados em mídia DVD. Ao longo das análises, ilustramos recortes dos diálogos das cenas que exemplificam os atendimentos realizados. Trabalhamos com três crianças: CA, CB, CC. Para este artigo, optamos pelos dados de CB e $\mathrm{CC}$ por uma questão de espaço do texto. Por questões éticas, utilizamos a sigla $\mathrm{CB}$, para Criança $\mathrm{B}$, que, à época, tinha 6 anos, e $\mathrm{CC}$, para Criança $\mathrm{C}$, que, à época, tinha 8 anos. Além disso, utilizamos $\mathrm{P} 1$ e $\mathrm{P} 2$ para nos referirmos às profissionais da Fonoaudiologia 1 e 2 que realizaram os atendimentos. $^{3}$

Antes de discorrermos sobre o embasamento teórico deste trabalho, destacamos que levamos em consideração a seguinte definição sobre o verbete lúdico: relativo a jogo ou divertimento; que serve para divertir ou dar prazer (FERREIRA, 2006). Essa definição é necessária para esclarecermos que a nossa análise não girou em torno de um modelo biomédico do tratamento da $\mathrm{SD}$, como a realização de exames clínicos, neuroimagem, ou baterias específicas de teste-padrão (MORATO, 2014), mas da interação e do engajamento dos interlocutores e do uso de diversos modos de linguagem para a negociação de referentes, por meio da narração de histórias, de jogos de montar, desenhos e pinturas, músicas infantis, jogos com bola, pescaria, brincadeiras com fantoches, jogos de associação de figuras com animais e com frutas. Todas essas situações ocorreram ao longo dos atendimentos, mas apenas as que estão relacionadas às análises deste artigo serão aqui mostradas.

Advogamos que esse modelo de trabalho é importante para contribuir com profissionais de clínicas fonoaudiológicas, creches, escolas e outros sujeitos que lidem com crianças, distúrbios, deficiências e patologias, uma vez que ancora o estatuto de atuação empírica em uma vertente mais ampla da linguagem, circunstanciada com questões 
de interação face a face, não ligadas à restrição de aspectos sistemáticos da língua.

A seguir, daremos continuidade à discussão de termos-chave da nossa pesquisa, cuja elucidação é necessária para o entendimento das análises.

\section{REFERÊNCIA E REFERENCIAÇÃO NAS INTERAÇÕES FACE A FACE}

Iniciamos este tópico fazendo um apanhado sobre os estudos da língua que Marcuschi (2000; 2001) considera pelo caminho de duas tradições contemporâneas da Linguística. A primeira foi dominada até os anos 60 pelo cunho estruturalista e descritivista da ciência positivista. No tocante ao cunho estruturalista, a língua é tida como produto da fonologia, da morfologia, da sintaxe e da semântica, com a perspectiva da significação dos enunciados baseada no conhecimento da língua, não interessando a contextualização dos enunciados.

Já a tradição da ação (inaugurada por Austin, Searle, Grice, pragmaticistas, analistas da conversação, etnometodólogos e por analistas do discurso) tem como apoio o funcionamento da língua em vários níveis de uso (MARCUSCHI, 2000; 2001). Não leva em conta tão somente a existência dos níveis estritamente linguísticos considerados pela perspectiva estruturalista, mas enfatiza a relevância de todos os demais processos, tais como o da enunciação, da modalidade, da cognição. O que permeia a essência dessa tradição é que falar ou escrever não são atividades autônomas, mas, sim, parte de uma atividade pública, coletiva, coordenada e colaborativa. Sendo assim, entendemos que "a referenciação na relação face a face é fruto de uma atividade colaborativa e não uma simples convenção linguística" (MARCUSCHI, 2001, p. 38).

Nesse sentido, Marcuschi (2001) contesta os estudos clássicos que configuram a língua como um espelho, ou seja, uma assertiva apresentando a língua como uma representação especular do mundo. No sentido oposto a essa ideia, o autor apresenta a metáfora da língua como uma lâmpada, por ser uma apresentação, um trato, uma forma de agir sobre o mundo. Para Marcuschi (2001), a língua é uma moeda, servindo para trocas, uma atividade social e cognitiva em contextos historicamente delineados e interativamente construídos. A nossa 
vertente caminha nessa direção profícua, uma vez que entendemos o processo de referenciação como instável, dinâmico e negociável, pois envolve múltiplos fatores sociocognitivos dos sujeitos dialógicos.

Para Cavalcante e Santos (2012), a identificação de estratégias de referenciação colabora para traçar o percurso dos sentidos no texto. Ademais, é necessário que o interactante faça levantamento de hipóteses, associe informações, faça inferências e ative conhecimentos prévios (linguísticos, textuais, enciclopédicos, intertextuais, contextuais), que colaboram para a construção do texto e da referenciação, à medida que esse sujeito se insere em uma situação interacional de negociação de sentidos, seja no universo virtual, seja no de interação face a face. Nessa mesma direção, apontamos para o fato de que as mesmas estratégias (levantamento de hipóteses e outras) devem ser tomadas na interação face a face, seja em situações naturalísticas entre adultos, adultos e crianças, seja na escola, na creche, na clínica, por exemplo. Conforme apontam Cavalcante e Santos (2012), em todo texto, e/ou discurso, o sujeito recategoriza o mundo real, a partir de informações precedentes e que estão disponíveis para receber predicações no transcorrer da interação. Dessa forma, o interagente pode realizar reinterpretações do elemento referido ou dar novos focos a ele.

Como ressaltamos anteriormente, a língua tem uma essência dinâmica que requer dos interlocutores um engajamento rumo à construção de um determinado objetivo, da recategorização, da ambiguidade, das reinterpretações, das refocalizações, dentre outros aspectos, que podem surgir na negociação de um referente.

Marcuschi $(2000 ; 2001)$ ainda aponta para o fato de a referenciação ser um processo de geração de domínios referenciais; nesse viés, a língua é muito mais do que simples mediadora, pois é explicada como atividade sociocognitiva e não apenas como forma cognoscitiva, ou mapeadora da realidade, que, por sua vez, é uma construção discursiva motivada. O que se verifica com isso é uma abordagem da língua como atividade intersubjetiva na, e pela qual, é constituído um modelo público de mundo (MONDADA; DUBOIS, 2003). Vemos, com isso, uma abordagem sobre a língua(gem) por uma trajetória oposta ao que circulou em meados do século XX a respeito da noção da referência como algo mentalista, ou seja, produto da cognição individual e não da relação social. 
Com esse percurso, entendemos que é nas situações de interação, e ancoradas nas operações sociocognitivas das atividades verbais e gestuais, que essas categorias e esses objetos do discurso (referentes) são constituídos, e, por isso, instáveis. Mondada e Dubois (2003) falam em instabilidade nesse processo de constituição, porque essas práticas não são imputáveis a um sujeito cognitivo abstrato, racional, intencional e ideal, solitário em face do mundo, mas a uma construção na intersubjetividade das negociações individuais e públicas do mundo.

Ancorados nessas assertivas, questionamos: a referenciação acontece apenas pela modalidade verbal? Procuraremos sanar essa questão ao longo do texto.

\section{SOBRE A REFERENCIAÇÃO MULTIMODAL}

Um conceito que vem ganhando espaço nos estudos da linguagem é o da multimodalidade, não apenas relacionada aos aspectos do texto escrito, mas, além disso, imbricada ao uso congruente de outros modos da linguagem, como, por exemplo, aspectos prosódicos, gestuais, contato visual, movimentos corporais, expressões faciais, dentre outros (MONDADA, 2005; MORATO, 2006; CUSTÓDIO FILHO, 2009).

Como contributo para os estudos acerca da multimodalidade em Aquisição da Linguagem, temos em Ávila-Nóbrega (2010) o termo Envelope Multimodal, uma categoria de análise que envolve, pelo menos, três modos de linguagem simultaneamente: produção vocal, visual e gestual. Isso implica dizer que há uma espécie de empacotamento, ou envelopamento, ou, ainda, um encapsulamento de sentido resultante da mescla da produção concomitante das nuances de linguagem mencionadas. Sendo assim, segundo essa perspectiva, os parceiros interativos não se colocam no mundo da linguagem por meio de uma linha de produção isolada, ou hierárquica, mas por meio de uma negociação sociocognitiva resultante do Envelope (ÁVILANÓBREGA; CAVALCANTE, 2012a; 2012b; 2015).

Diante disso, podemos dizer que advogamos o conceito de referenciação multimodal como sendo o processo pelo qual os objetos de discurso (referentes) são negociados pelos interactantes, nesse dinamismo da linguagem, por meio do uso congruente dos muitos modos, conforme apontamos anteriormente (ÁVILA-NÓBREGA, 
2017). No nosso trabalho, respondendo à questão colocada ao final do item anterior, entendemos que a partilha de referentes do mundo não se dá apenas pelo aspecto verbal da língua.

Os sujeitos interativos têm certo domínio e intencionalidade sobre o que se pretende dizer, ou como agir, em cenas interativas, mas não total domínio ou controle sobre a negociação de sentidos, uma vez que a interação não é construída apenas por um indivíduo, sobre quem haveria o status de supervalorização no diálogo. Isso é o que podemos observar, por exemplo, em contextos dialógicos com as crianças, tanto circundados na própria família quanto em atendimentos terapêuticos. As cenas não são construídas tendo em vista apenas a experiência daquele que se dirige à criança. Muita coisa pode ser posta em xeque, a partir das surpresas que a criança pode trazer para o momento do engajamento conjunto (TOMASELLO, 2003).

\section{REFERENCIAÇÃO MULTIMODAL EM MOMENTOS LÚDICOS}

Tendo discorrido sobre as premissas teóricas envolvendo referenciação e multimodalidade, mostraremos, a seguir, dois recortes dos atendimentos realizados na clínica. ${ }^{4}$ Em nossa descrição, apresentaremos a data em que a sessão ocorreu, a idade das crianças e uma breve descrição do contexto situacional, uma vez que consideramos importante circunstanciarmos como estavam distribuídos os participantes no momento do atendimento. Como estamos nos referindo a interações de crianças com profissionais da linguagem, acreditamos que o processo de negociação de sentidos se deu com a participação das terapeutas com as crianças.

Destacaremos duas relações de referenciação que Ávila-Nóbrega (2017) elabora em seu trabalho: a reiteração e a associação. A primeira retoma algum objeto de discurso anteriormente inserido na cena, o qual muitas vezes ainda não foi satisfatoriamente negociado. Além disso, pode ser estabelecida para o amadurecimento e/ou manutenção de algum tópico na negociação dos sentidos; não se confunde com a repetição; já a segunda desloca o interactante para outras entidades na atenção conjunta (tempo, lugar, pessoa, objeto, situação); por exemplo: um brinquedo que pode ser usado como telefone mesmo sem ter as características físicas de tal. Vale lembrar que essas relações emergem 
com um estatuto multimodal, como resultado do engajamento dos parceiros. Vejamos como isso ocorre nas cenas.

RELAÇÕES DE REITERAÇÃO E DE ASSOCIAÇÃO NA REFERENCIAÇÃO MULTIMODAL

\section{DADOS DE CB}

Idade de CB: 6 anos, 7 meses e 28 dias.

Sessão: 06/03/15

Contexto: P1 e P2 estão sentadas à mesa com $\mathrm{CB}$. P1 está sentada ao lado esquerdo de $\mathrm{CB}$. P2, sentada diante de $\mathrm{CB}$, mostra figuras que indicam sentidos opostos (em cima, embaixo, quente, frio, limpo, sujo). Ambas as profissionais fazem gestos e sons vocais para ilustrar as figuras apresentadas no atendimento.

\section{RECORTES E ANÁLISES DO DIÁLOGO ENTRE TERAPEUTAS E CB}

P2: Olha, CB. Olha, CB. Vou mostrar as duas imagens pra você, viu? (Olhando para $\mathrm{CB}$ e mostrando duas figuras diferentes com as mãos levantadas em frente à criança)

P2: Primeiro, o gatinho tá em cima da mesa. Ele tá em cima. Onde é em cima? (Coloca com a mão direita a figura sobre o cartaz que está na mesa e permanece com a mão esquerda levantada com a outra figura).

P1: (Bate repetidas vezes com a mão esquerda sobre a mesa olhando para $\mathrm{CB})$.

P2: (Bate repetidas vezes com a mão direita sobre a mesa olhando para $\mathrm{CB})$.

CB: (Acompanha com o olhar os movimentos de P2. Em seguida, bate à mesa com a mão direita repetindo o gesto de $\mathrm{P} 1$ e de $\mathrm{P} 2$ e continua olhando para P2).

P1: E embaixo? (Inclina o corpo em direção à parte inferior da mesa).

P2: Aí depois ele tá embaixo. Onde é embaixo? Ó! (Coloca a figura com a mão direita sobre o cartaz olhando para CB e leva o outro braço para a parte inferior da mesa). 
P2: Ele tá embaixo da mesa, debaixo. Aqui, ó, embaixo. (Aponta a figura com o dedo indicador esquerdo olhando para a figura e depois coloca a mão esquerda novamente na parte inferior da mesa).

CB: (Coloca o braço direito na parte inferior da mesa e alterna o olhar entre o local e P2).

P1: (Movimenta o corpo acompanhando as ações de CB).

Nessa primeira parte do diálogo, houve uma estratégia de repetição dos termos em cima, embaixo, tanto por parte de P2, como pelas ações de P1. É importante destacarmos que essas estratégias não foram produzidas apenas pelo aspecto verbal da linguagem. O direcionamento do olhar das profissionais, a produção oral e os movimentos corporais que elas fizeram colaboraram para que $\mathrm{CB}$ percebesse qual o objetivo das terapeutas, ao solicitarem da criança a correspondência do sentido dos termos produzidos.

Por sua vez, CB, direcionando o olhar para $\mathrm{P} 2$, bateu à mesa repetidas vezes, como uma forma de ênfase gestual para corroborar onde estava localizada a parte superior de algum lugar. Em seguida, a criança inclinou o corpo para a parte inferior da mesa, como uma estratégia para mostrar onde se localizava a parte de baixo. O uso dos modos de linguagem que as profissionais fizeram parece ter ativado processos cognitivos de $\mathrm{CB}$, por meio da repetição de termos e movimentos corpóreos. Em seguida, apresentamos a continuação do diálogo:

P1: Cadê? Cadê? Pega pra mim o gatinho, a figura que o gatinho tá em cima da mesa. Em cima. (Olha para CB, arqueia as sobrancelhas, levanta o dedo indicador esquerdo e depois aponta em direção às figuras na mesa).

CB: (Alterna o olhar entre P1 e as figuras e depois aponta com o dedo indicador direito para uma das figuras).

P1: Não! Que o gatinho tá em cima. (Faz o movimento de negação com a cabeça e alterna o olhar entre $\mathrm{CB}$ e as figuras).

CB: (Alterna o olhar entre P1 e as figuras e em seguida aponta para a segunda figura).

P1: É, é essa. Ó! O gatinho tá em cima da mesa, tá vendo? (Sorri, faz movimento com a cabeça em sinal positivo, retira a figura de cima da mesa e mostra a $\mathrm{CB}$ ). 
As estratégias usadas nesta parte da cena mostram a relação de reiteração emergindo, quando as profissionais indagam $\mathrm{CB}$ a respeito da figura que mostra o animal sobre a mesa. A criança, por sua vez, mesmo não apontando para a gravura adequada, corresponde ao jogo interativo, negociando as estratégias com o apontar com o dedo indicador direito e com o olhar.

Com o auxílio da multimodalidade que P1 usa, ao balançar a cabeça em sentido negativo, ao produzir vocalmente as sentenças negativas e ao alternar o olhar entre a criança e a figura, CB se reorganiza e corresponde aos objetivos de sua interactante apontando para a figura correta. Vale destacar que CB é uma criança que interage bastante por meio do uso de gestos, movimentos corporais, expressões faciais (que não são objetivo da análise neste artigo) e pelo direcionamento do olhar. Poucas vezes a criança produziu termos orais. Alguns deles só aparecem em outras cenas que compõem o acervo da coleta. Portanto, os modos visuais e gestuais de CB dão suporte à "ausência" da produção vocal, mas não se desconfiguram como multimodais.

$\mathrm{O}$ diálogo continua rumo à negociação de sentido de mais antônimos, com a estratégia da associação.

P2: Tu usa meia? Meia, a meia que a gente bota antes de colocar o tênis. (Olhando para $\mathrm{CB}$, baixa a mão esquerda em direção ao pé esquerdo).

P1: Olha aqui a meia de CB. (Sorrindo e olhando para CB, baixa a mão direita e toca a meia da criança fazendo uma entonação com falsetto).

CB: (Olha para P1 e sorri).

P2: Ó a meia, ó. Só que aqui a meia tá suja. A meia tá suja ó. (Com a mão direita coloca a figura sobre a mesa e, olhando para a criança, faz o gesto de sujo, balançando a mão direita diante do nariz e franzindo o rosto).

P1: Hum! (Com a mão esquerda balançando diante do nariz, faz sinal de sujo com o rosto franzido).

CB: (Olha para a figura da meia suja e depois olha para P2).

P2: Suja!

CB: (Olha para a figura, sem esboçar fisionomia).

P2: Só que depois que a mãe de CB lavou a meia dele, aí a meia ficou limpa. Bem limpinha, né? (Coloca a figura sobre o cartaz na mesa). 
P2: A meia suja, a meia limpa. (Aponta com o dedo indicador direito sobre uma figura, em seguida sobre a outra).

CB: (Acompanha com o olhar a alternância das figuras feita pelo apontar de P2. Em seguida, cheira uma das figuras e faz o sinal de sujo com a mão direita, balançando diante do nariz e com o rosto franzido). P1: Hum! Essa, ó. Essa, ó. (Balança a mão esquerda diante do nariz, fazendo gesto de sujo, após apontar para a figura).

P2: Tá suja! (Balança a mão direita diante do nariz, fazendo gesto de sujo).

CB: (Baixa a cabeça e cheira a figura. Em seguida, faz o gesto de sujo).

Nesse recorte, encontramos estratégias que as profissionais utilizaram para fazer uma associação de situações para CB. Toda a construção sequencial de sentidos, ao apontarem para a meia, mencionarem que é uma peça usada antes do tênis e que, ao ser lavada pela mãe, a peça fica limpa, faz com que CB corresponda à negociação de sentido do antônimo sujo/limpo introduzido pelas terapeutas.

Notemos que, mais uma vez, as estratégias de referenciação não são usadas apenas com o aspecto verbal, mas com o direcionamento do olhar, com os movimentos corporais, com o falsetto, com os gestos e as expressões faciais para orientar o sentido das palavras.

Quando é mencionado que Só que depois que a mãe de $C B$ lavou a meia dele, ai a meia ficou limpa. Bem limpinha, né?, percebese uma retomada de situações, as quais, certamente, a criança já teria vivenciado, como o fato de alguma peça de roupa se tornar limpa após ser lavada.

Nessa mesma situação, a relação de associação emerge, quando existe uma ligação entre a figura do sujo/limpo com a própria meia de $\mathrm{CB}$ e com situações cotidianas vividas em contexto familiar.

CB insere na atividade interativa uma ação que P1 e P2 não haviam realizado: cheirar a figura. Isso evoca o sentido negociado conjuntamente pelas terapeutas e pela criança ao associar sujo/limpo com o odor.

P2: Cadê a meia limpa? Tá cheirando. A meia limpa. (Faz um gesto com os dedos das duas mãos em direção ao nariz, como se trouxesse o ar para si e sorri olhando para $\mathrm{CB}$ ). 
P2: Ó a meia limpa, bem limpinha com cheirinho de amaciante. (Aponta com o dedo indicador direito para a figura).

P1: Ó a limpa, ó a limpa, ó a limpa. (Pega a figura com a mão esquerda e a leva ao nariz para cheirá-la. Olha para $\mathrm{CB}$ e, após colocar novamente a figura sobre a mesa, aponta para ela com o dedo indicador esquerdo). P2: Cadê a suja? A suja, CB. Meia suja, ó. (Olha para CB e faz os mesmos gestos de sujo, balançando a mão diante do nariz).

P1: Mostra agora onde tá a meia suja. (Inverte a posição das figuras sobre a mesa).

CB: (Escolhe a figura que corresponde a sujo e faz o gesto diante do nariz).

A cena continua sendo estabelecida pelos três participantes, e o uso da relação de reiteração emerge novamente, quando a expressão cadê a meia limpa evoca o primeiro momento do diálogo sobre a meia. Além disso, o direcionamento do olhar e o gesto com os dedos das duas mãos em direção ao nariz ocorrem simultaneamente.

P2 continua engajada em manter o foco da criança na negociação conjunta do sentido de meia limpa, quando associa a expressão ao cheirinho de amaciante e aponta com o dedo indicador direito para a figura.

$\mathrm{CB}$, ao final do tópico meia limpa/suja, corresponde ao engajamento de P1 e de P2, escolhendo a figura que indica o sentido de sujo, cheira a figura e faz expressões faciais e movimentos com a mão esquerda diante do nariz, retomando o enquadre anterior em que os três parceiros se divertiam fazendo os gestos e as expressões faciais relacionados ao contexto de sujeira. A associação também está no fato de $\mathrm{CB}$ e as terapeutas usarem as nuances simultâneas da linguagem com expressões que remetem à sujeira e à limpeza.

No próximo item, analisaremos recortes do diálogo de uma das cenas entre as terapeutas e CC.

\section{DADOS DE CC}

Idade de CC: 8 anos, 8 meses e 8 dias Sessão: 07/11/14 
Contexto: P1 e P2 contam a história da Bela Adormecida para CC, sentadas no chão, mostrando imagens do livro.

\section{RECORTES E ANÁLISES DO DIÁLOGO ENTRE TERAPEUTAS E CC}

P1: Vamos sentar aqui com a tia? Vamos sentar? (Em pé na sala com CC). P1: Vamos sentar, tu já, tu já escutou a historinha da Bela Adormecida? Já?

CC: Tem musca? (Sentando ao chão com P1).

P1: Já? Ó aqui ó. Eu vou contar pra tu certo? (Olha para P2 que acaba de entrar na sala).

P1: E ela também vai ajudar a gente, tá certo?

CC: Ó meu cabelo! (Segura o cabelo com as duas mãos e mostra para $\mathrm{P} 1)$.

P1: O cabelo grande! Olha o meu, tu gostou do meu cabelo? (Pega com a mão esquerda o cabelo, coloca para a frente e passa a mão várias vezes olhando para $\mathrm{CC}$ ).

CC: Cabelo bonito. (Olhando para P1, coloca o cabelo para o lado esquerdo do corpo e passa a mão nele repetidas vezes).

P1: Cabelo bonito, né? (Olhando para CC).

P2: O cabelo dela é bonito, né? Oia só! (Passa a mão esquerda no cabelo de P1 e alterna o olhar entre P1 e CC).

$\mathrm{CC}$ : (Inc) ${ }^{5}$

P1: É lindo o de CC!

P2: É lindo, CC! O cabelo de CC. (Passa a mão direita no cabelo de CC e olha para ela).

P2: E esse, esse óculos, CC? (Olhando para a criança e sorrindo).

CC: E ta no cabelo vi lá assim. (Inc).

P2: Tu sabe meu nome? (Toca com a mão esquerda espalmada o próprio corpo).

CC: (Inc). E amarra e ó!

P2: Tu sabe meu nome?

P1: Hein, CC, tu sabe o nome dela? Vamos saber, vamos perguntar o nome dela? (Olhando para a criança).

P2: Então vamos ler a historinha? (Segurando o livro e olhando para a criança).

P2: Ó, de quem é a historinha olha! (Mostra a capa do livro diante de CC). 
Na primeira parte desse diálogo, P2 procura organizar a situação para uma narração de história infantil. No entanto, CC insere uma nova informação na cena, quando chama a atenção para o seu cabelo. A partir disso, P1 e P2 correspondem à interação, reiterando várias vezes o termo cabelo multimodalmente: tocam os próprios cabelos, tocam o cabelo uma da outra e P2 toca o cabelo de CC, além da alternância de olhares e produção oral.

Ao final desse primeiro recorte, $\mathrm{P} 2$, na tentativa de reorganizar os objetivos do atendimento (contar a história), mostra a capa do livro para CC e questiona a respeito de quem se refere o livro. Uma relação de reiteração emerge novamente, alinhando o diálogo à primeira parte.

CC: Oia a fadinha tem um mermo do cabelo (inc). (Aponta com o dedo indicador esquerdo para a capa do livro).

P2: Tem um cabelo lindo né? Loira. (Passa a mão direita invertida sobre a capa do livro e alterna o olhar entre CC e o livro).

P2: De quem é a historinha, tu sabe? (Olha para a criança).

CC: (Inc). (Aponta com o dedo indicador esquerdo para a capa do livro).

P2: É da Bela adormecida. Né da Cinderela não. (Olha para CC e abre o livro).

P2: Vamos ler a historinha? Vamos? (Olha para CC e ajusta o livro aberto diante da criança).

CC: (Inc).

P2: Ó, é a Bela adormecida. (Olhando para o livro).

P2: Vamos lá, quem é essa daqui? Tu sabe quem é? (Olha para CC e aponta com o dedo indicador direito para a personagem no livro).

CC: (Inc).

P2: É a bruxa má! (Arqueia as sobrancelhas, aponta repetidas vezes para a personagem no livro e olha para $\mathrm{CC}$ ).

CC: A busakeka. (Aponta com o dedo indicador esquerdo para a personagem e olha para $\mathrm{P} 2$ ).

P2: É, é! É a keka. (Sorri e olha para P1).

P1: Bruxa keka. (Sorri e olha para P2 e para CC).

P2: Vamos ler, ó. (Olha para o livro). 
CC continua direcionando a cena para o tópico cabelo por meio da reiteração e, dessa vez, associa o termo ao cabelo da personagem do livro, alternando o olhar para P1 e para a capa do livro, apontando e produzindo oralmente a sentença "Oia a fadinha tem um mermo do cabelo".

Ao ser questionada por $\mathrm{P} 2$ a respeito de quem é a história do livro, CC produz algo incompreensível, mas $\mathrm{P} 2$ interpreta como se CC mencionasse o nome de outra personagem (no caso, a Bela Adormecida, conforme o diálogo arquivado no acervo coletado). Aqui, percebemos uma tentativa de reelaboração das interactantes diante de um episódio de associação de personagens de dois contos infantis: a Cinderela e a Bela Adormecida.

Como uma breve discussão, podemos mencionar que os recortes de dados de $\mathrm{CB}$ e de CC, apresentados neste texto, evocam duas relações de referenciação relevantes para a negociação de sentidos das crianças com as terapeutas: a reiteração e a associação. Outros aspectos poderiam ser destacados, no entanto, fugiriam ao objetivo do presente texto.

Foi percebido que a reiteração tanto pode ser direta, quando há uma retomada do mesmo termo usado anteriormente, quanto indireta, caso haja alguma variação no termo, sem perder o seu sentido (embaixo, debaixo, meia limpa, roupa limpa). O toque com as mãos na mesa, as batidas na mesa, o direcionamento do corpo e do olhar entre os parceiros, ou para os espaços físicos envolvidos na cena, atuam como congruentes para a negociação conjunta dos objetos de discurso.

A referenciação por associação também emerge pelo uso multimodal e evoca outras entidades para a negociação de sentido com a criança (amaciante para meia limpa e cheirosa, cheirar a figura para representar os odores, Cinderela e Bela Adormecida, Bruxa Má e Bruxa Keka).

\section{CONSIDERAÇÕES}

Este trabalho aponta para a importância do uso de várias estratégias interativas para a negociação de sentidos, na interação com a criança com Síndrome de Down. No entanto, é importante ressaltar que essas relações de referenciação e as estratégias multimodais 
mencionadas nos recortes dos diálogos não são exclusivas para o atendimento fonoaudiológico, tampouco para crianças com síndromes ou patologias da linguagem.

Conforme vimos anteriormente, as relações de referenciação são usadas para a negociação conjunta de sentidos tanto no texto escrito quanto nos diálogos face a face. Elas evocam o funcionamento de aspectos cognitivos (categorização, memória, percepção, frames etc.) que serão reorganizados no entorno social.

Ressaltamos a importância de contextos lúdicos na facilitação do engajamento de crianças, seja em uma clínica, seja em outras esferas sociais, para a formulação de referentes no mundo real.

CHILDREN WITH DOWN SYNDROME: REFERENCING AND MULTIMODALITY IN PLAYFUL CONTEXT

\begin{abstract}
Our aim is to present the use of the multimodal referencing (ÁVILA-NÓBREGA, 2017) of two children with Down syndrome, in the joint engagement in playful contexts. Regard DS, theoretical postulates of Pueschel (2002) will be presented. Regard referencing, we mention the relations of reiteration and association. About what we conceive by multimodality, we have based McNeill's studies (1985) and defend the notion of joint engagement, according to studies by Tomasello (2003). Our data were collected in the Speech Therapy Clinic of the Universidade Federal da Paraíba, and the videos containing the data collected in the clinic have an average of 30 minutes duration.
\end{abstract}

KeYwords: Multimodal referencing, Down syndrome, joint engagement.

\title{
NIÑOS CON SÍNDROME DE DOWN: REFERENCIA Y MULTIMODALIDAD EN CONTEXTO LÚDICO
}

\section{RESUMEN}

Nuestro propósito es presentar el uso de la referencia multimodal (ÁVILANÓBREGA, 2017) de dos niños con Síndrome de Down, en el compromiso conjunto en contextos lúdicos. Sobre el $\mathrm{SD}$, se presentarán postulados de Pueschel (2002) . Sobre la referencia, mencionamos las relaciones de la reiteración y de la asociación. Para comentar nuestros conceptos sobre multimodalidad, tomamos como base los estudios de McNeill (1985) y para 
defender la noción de compromiso conjunto, nos basamos en los estudios de Tomasello (2003). Nuestra recolección de datos tuvo lugar en la Clínica de Fonoaudiología de la Universidad Federal da Paraíba, y los videos que contienen los datos recogidos en la clínica tienen un promedio de 30 minutos de duración.

Palabras Clave: Referencia multimodal., síndrome de Down, compromiso conjunto.

\section{Notas}

1. As três crianças são filhas da mesma mãe e as três têm Síndrome de Down. Com o acompanhamento das crianças e da mãe na Clínica-Escola da UFPB, pode-se entender que a variação cromossômica delas está nos cromossomos 14 e 21, o que agrega grandes chances de mais reproduções com a síndrome na família.

2. Os dados apresentados neste trabalho foram aprovados pelo Comitê de Ética da UFPB, sob o processo 46076215.8.0000.5188.

3. O pesquisador deste estudo não fazia atendimentos, mas participava como observador.

4. Conforme explicado na introdução, acerca da coleta de dados.

5. Indica que a criança produziu algo incompreensível.

\section{REFERÊNCIAS}

ÁVILA-NÓBREGA, Paulo Vinícius. Dialogia mãe-bebê: a emergência do envelope multimodal em contextos de atenção conjunta. 2010. $165 \mathrm{f}$. Dissertação (Mestrado) -Universidade Federal da Paraíba, João Pessoa, 2010. . Referenciação multimodal de crianças com Síndrome de Down em engajamento conjunto. 2017. 206 f. Doutorado (Tese em Linguística)Universidade Federal da Bahia, João Pessoa, 2017.

. CAVALCANTE, Marianne Carvalho Bezerra. Aquisição de linguagem em contextos de atenção conjunta: o envelope multimodal em foco. Revista Signótica. v. 24, n. 2, p. 469-491, jul./dez. 2012a. 
. Aquisição de linguagem e dialogia mãe-bebê: o envelope multimodal em foco em contexto de atenção conjunta. Revista Investigações, v. 25, n. 2, p. 157-183, jul. 2012b.

- O envelope multimodal em aquisição de linguagem: momento do surgimento e pontos de mudanças. IN: CAVALCANTE, Marianne Carvalho Bezerra; FARIA, Evangelina Maria Brito de (Org.). Cenas em aquisição da linguagem: multimodalidade, atenção conjunta e subjetividade. João Pessoa: Editora da UFPB, 2015. p. 11-44.

CAVALCANTE, Mônica Magalhães; SANTOS, Leonor Werneck dos. Referenciação e marcas de conhecimento partilhado. Linguagem em (Dis) curso, Tubarão, SC, v. 12, n. 3, p. 657-681, set./dez. 2012.

CUSTÓDIO FILHO, Valdinar. Aspectos multimodais envolvidos na construção da referência. In: CONGRESSO INTERNACIONAL DA ABRALIN, 6, 2009. João Pessoa. Anais... João Pessoa: Ideia, 2009, p. 2927-2936. (CD-ROM).

. Reflexões sobre a recategorização referencial sem menção anafórica. Linguagem em (Dis)curso, Tubarão, SC, v. 12, n. 3, , p. 839-858, 2012.

FERREIRA, Aurélio Buarque de Holanda. Dicionário da língua portuguesa. Rio de Janeiro: IBGE, 2006.

KRESS, Gunther R; VAN LEEUWEN, Theo. Reading images: the grammar of visual design. London, New York: Routledge, [1996], 2006.

MARCUSCHI, Luiz Antônio. Referenciação e progressão tópica: aspectos cognitivos e textuais. Revista do GELNE, v. 2, n.2, p. 1-11, 2000.

. Atos de referenciação na interação face a face. Caderno de Estudos Linguísticos, Campinas, v. 41, p. 37-54, jul./dez. 2001.

MCNEILL, David. So you think gestures are nonverbal? Psychological Review,v. 92, n.3, p. 350-371, jul. 1985.

. Hand and mind: what gestures reveal about thought. Chicago: University of Chicago Press, 1992.

. Gesture: a psycholinguistic approach. In: BROWN, Keith; Anderson, Anne. (Eds.). The encyclopedia of language and linguistics. Amsterdam, Boston: Elsevier, 2006. p. 58-66.

MONDADA, Lorenza. A referência como trabalho interativo: a construção da visibilidade do detalhe anatômico durante uma operação cirúrgica. In: $\mathrm{KOCH}$, Ingedore Grunfeld Villaça. G. V.; MORATO, Edwiges Maria; BENTES, Anna Christina (Orgs.) Referenciação e discurso. São Paulo: Contexto, 2005. p. 11-31. 
; DUBOIS, Danièle. Construção dos objetos de discurso e categorização: uma abordagem dos processos de referenciação. In: CAVALCANTE, Mônica Maria; RODRIGUES, Bernadete Biasi; CIULLA, Alena (Org.). Referenciação. São Paulo: Contexto, 2003. p. 17-52.

MORATO, Edwiges Maria. Gestão do tópico e relevância conversacional na interação entre afásicos e não-afásicos, ou quando uma mão lava a outra. Cadernos de Estudos Linguísticos, Campinas, v. 48, n. 1, p. 105-113, 2006.

. Metodologia em neurolinguística. In: GONÇALVES, Adair Vieira; GÓIS, Marcos. Lúcio de Sousa. (Orgs.) Ciências da Linguagem: o fazer científico. v. 2. Campinas: Mercado de Letras, 2014. p. 281-320.

PUESCHEL, Siegfried M. Síndrome de Down: guia para pais e educadores. Campinas, SP: Papirus, [1993] 2002. 299 p.

RUTHROF, Horst. The body in language. London and New York: Cassell, 2000. 193 p.

TOMASELLO, Michael. Origens culturais da aquisição do conhecimento humano. Tradução de Claudia Berliner. São Paulo: Martins Fontes, 2003.

Submetido em 19 de setembro de 2017

Aceito em 20 de fevereiro de 2018

Publicado 30 de novembro de 2018 